\title{
MEDICAL COLLECTIONS TODAY
}

\author{
Maie Toomsalu ${ }^{1}$, Pille Randjärv ${ }^{2}$ \\ ${ }^{1}$ Institute of Anatomy, University of Tartu, Tartu, Estonia \\ ${ }^{2}$ Science Centre AHHAA, Tartu, Estonia
}

\begin{abstract}
In 1890 Professor of Anatomy August Antonius Rauber founded a museum of anatomy at the Old Anatomical Theatre in Tartu (Dorpat) in order to illustrate his lectures and to improve the students' knowledge. As Rauber lectured in German, but most students were Russians, illustrating lectures with models and original specimens was of great significance. Unfortunately, a great number of exhibits of Rauber's museum, although not all, have been lost in wars. In 1999, the institutes moved from the Old and New Anatomical Theatres to the new building of Biomedicum. This, however, could not accommodate the collection of pathological anatomy which had been collected over 200 years, and it remained in the Old Anatomical Theatre. The Club of Friends of the Old Anatomical Theatre succeeded in writing a project to keep the Old Anatomical Theatre and the excellent collection of pathological anatomy alive.

In September 2005, a medical exhibition was opened in the same Old Anatomical Theatre again, now under the name of the Medical Collections of the Faculty of Medicine of the University of Tartu. The exhibition also acquired a number of new functions.

During 2011, the Medical Collections of the Faculty of Medicine cooperated with the Estonian Sports Museum, and the collections were displayed in their exhibition hall.

In 2012, the medical exhibition moved to the premises of the Science Centre AHHAA, and since then, educational programmes have been developed.
\end{abstract}

Keywords: medical collection; wet specimen; mummification; anatomical model; skeleton; bones; educational programmes 
In 1890, Professor of Anatomy August Antonius Rauber founded a museum of anatomy at the Old Anatomical Theatre in Tartu (Dorpat) for illustrating his lectures and improving the students' knowledge. As Rauber lectured in German, but most students were Russians, illustrating lectures with models and original specimens was of great significance. Rauber was highly skilled at anatomical preparation, and he also trained the preparator Aleksander Reinvald who was of Estonian ethnicity. Rauber writes, "Since then, the lecture hall has been uninterruptedly teeming with happy life; it has found its rightful place among the students and, in all likelihood, will not disappear from the scene in the future" [1]. Rauber considered the museum most essential for the training of medical students. In the afternoons, after the lectures, the exhibition was open for students of other faculties and townspeople. On Fridays, the exhibition could be visited by housewives.

In his 1895 publication Über die Einrichtung von Studiensälen in anatomischen Instituten, Professor Rauber emphasized that people of other specialities should also visit the collections. "The exhibition hall, which entirely lacks the frightening aspect, is appropriate for students of other faculties for acquiring knowledge about their bodies through visualized teaching. If such an exhibition hall is able to exert its positive influence outside the Faculty of Medicine and encourage non-medics to study anatomy, it is, in my opinion, a sufficiently great achievement to justify their foundation at the institutes of anatomy in the future" [1].

Unfortunately, a great number of exhibits of Rauber's museum, although not all, have been lost in the turmoil of wars. In 1999, the Institutes of Anatomy, Histology, Pharmacology, Forensic Medicine and Operative Surgery moved from the Old Anatomical Theatre and the Institutes of Pathological Anatomy and Physiology from the New Anatomical Theatre to the new building of Biomedicum. This, however, could not accommodate the collection of pathological anatomy which had been collected over 200 years, and this remained in the Old Anatomical Theatre. It was taken care of by Aari Talve, Senior Laboratory Assistant of the Institute of Pathological Anatomy and Forensic Medicine. To raise money for the renovation of the Old Anatomical Theatre, which was in bad repair, the people interested in the matter founded the Club of Friends of the Old Anatomical Theatre. A group of club members managed to get money from the Ministry of Education and Research for renovating the preserved medical specimens and preparing them for the exhibition. In September 2005, a medical exhibition was opened in the same Old Anatomical Theatre again, now under the name of the Medical Collections of the Faculty of Medicine of 
the University of Tartu. The exhibition also acquired a number of new functions. It became a part of the education system through which school students and adults can learn about the hazards of risk behaviour. Attempts were made to make schoolchildren interested in biology and medicine. The medical exhibition also became a place for self-reflection. The exhibition has also been well received by disabled people, as it gives them strength to cope with their lives. Specimens, models and posters tell the story of the research and discovery of the human organism, which has been increasingly dependent on the development of technology. The exhibits have been of great interest for children and adult artists, and the pictures inspired by the exhibition have been of great interest for visitors.

During 2011, the Medical Collections of the Faculty of Medicine cooperated with the Estonian Sports Museum, and the collections were displayed in their exhibition hall.

In 2012, the medical exhibition moved to the premises of the Science Centre AHHAA, and close cooperation with the Centre began. The staff of the medical collections provide explanations on medical specimens and models to visitors and, within their capabilities, participate in AHHAA's educational programmes.

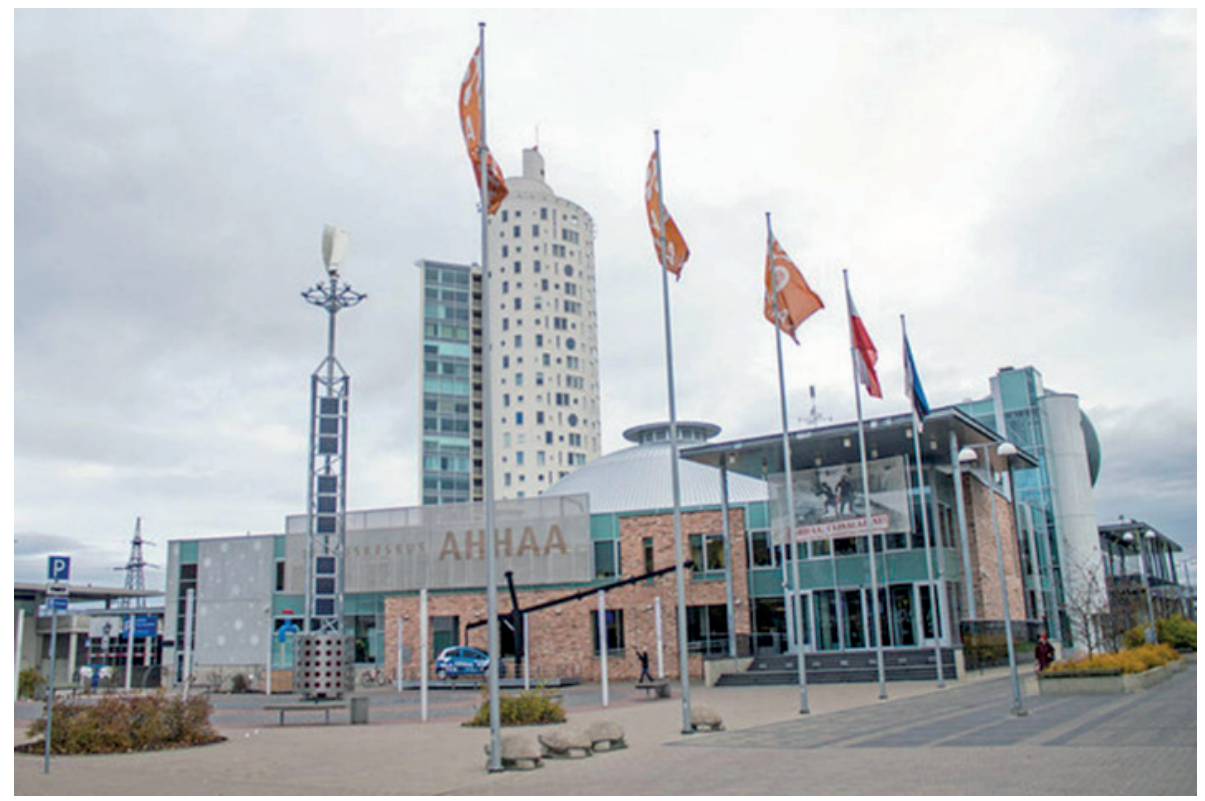

Science Centre AHHAA 
In cooperation with the Estonian National Institute for Health Development and Tartu Department of Social Welfare and Health Care, social advertisements and leaflets have been published that promote healthy ways of life and increase awareness about risk behaviour. The visitors' interest in them is great and the display stands have to be constantly refilled.

At present, the AHHAA Science Centre team of educational programmes conductors is headed by Pille Randjärv.

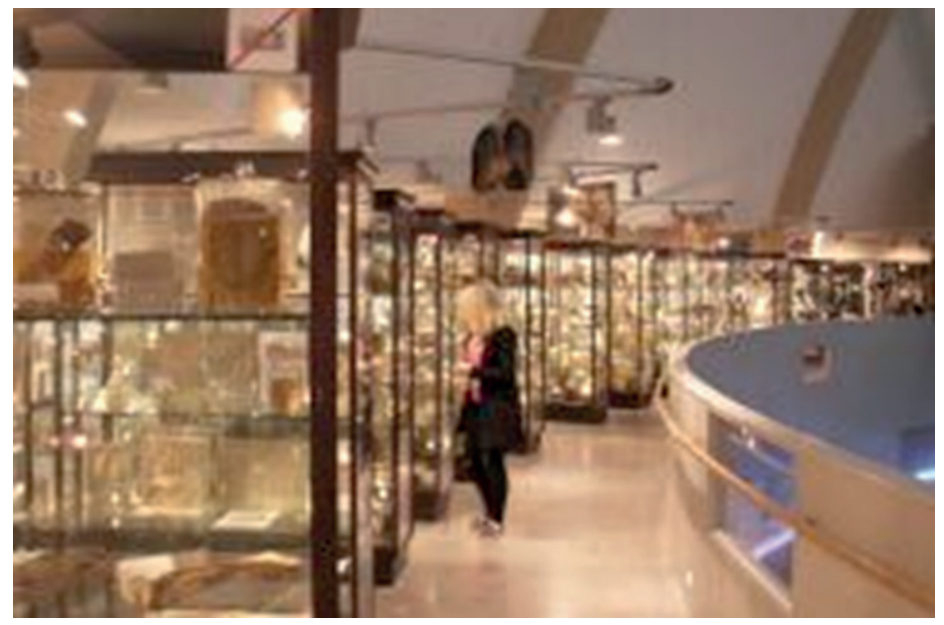

Exhibition

of medical

collections

Interested young visitors get rubber gloves and can take plastinated specimens in their hands and examine them closely under the supervision of the tour guide. They can get detailed explanations and take a close look at wet specimens in jars.

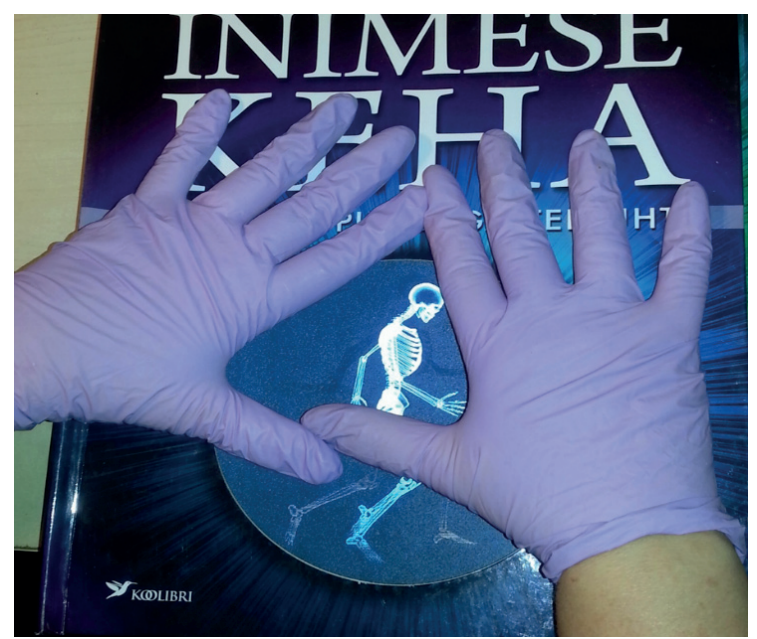




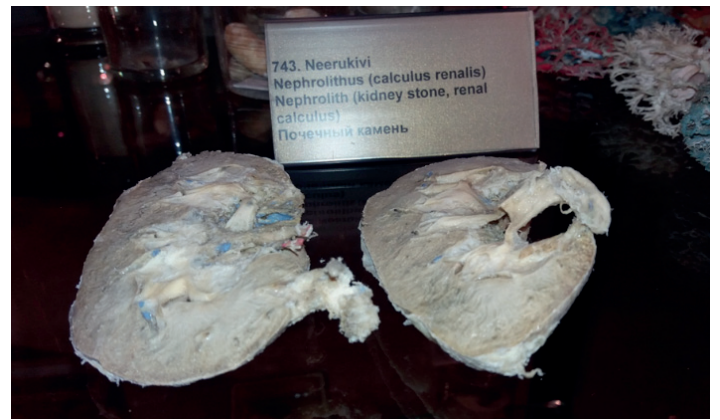

- Plastinated specimen of kidney
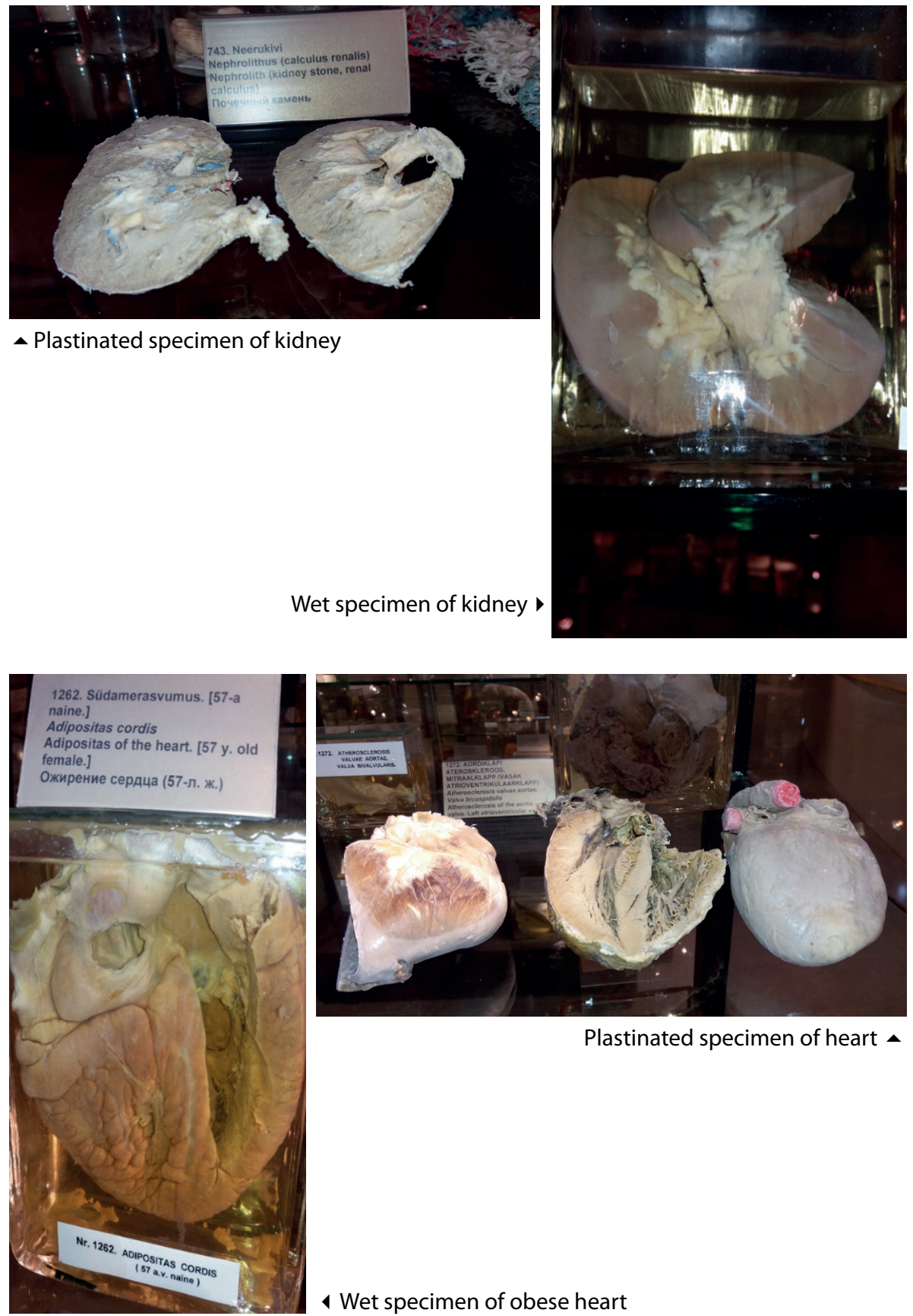

Plastinated specimen of heart $\Delta$

Wet specimen of obese heart 


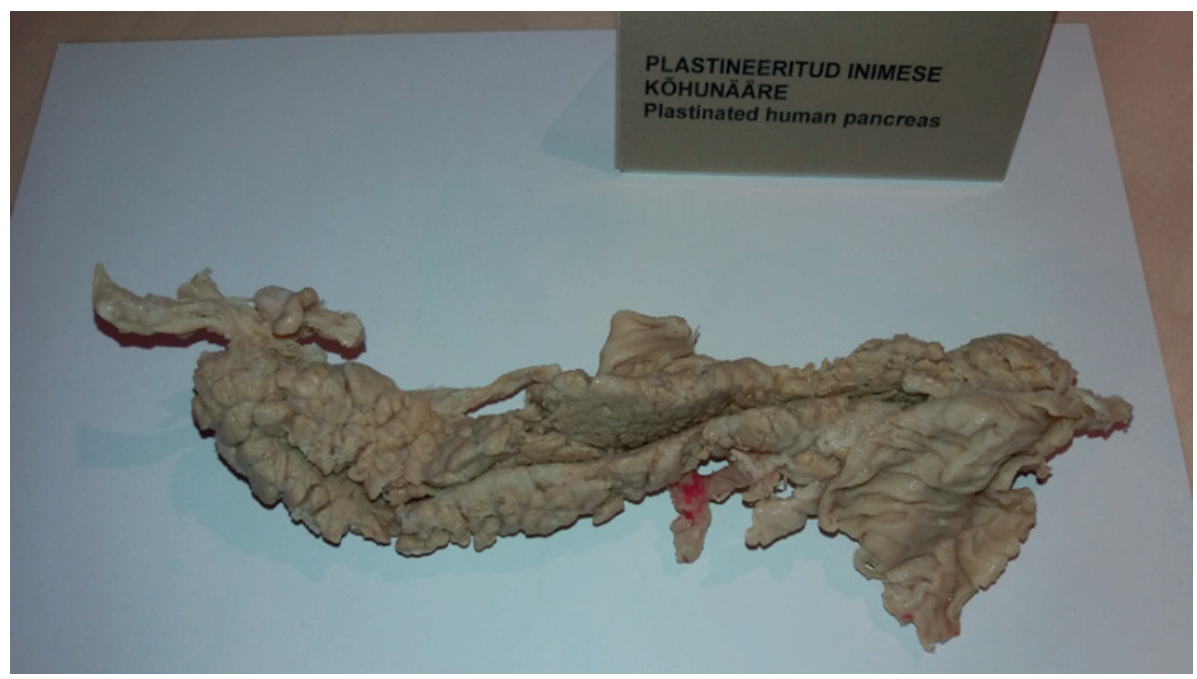

\section{Plastinated pancreas}

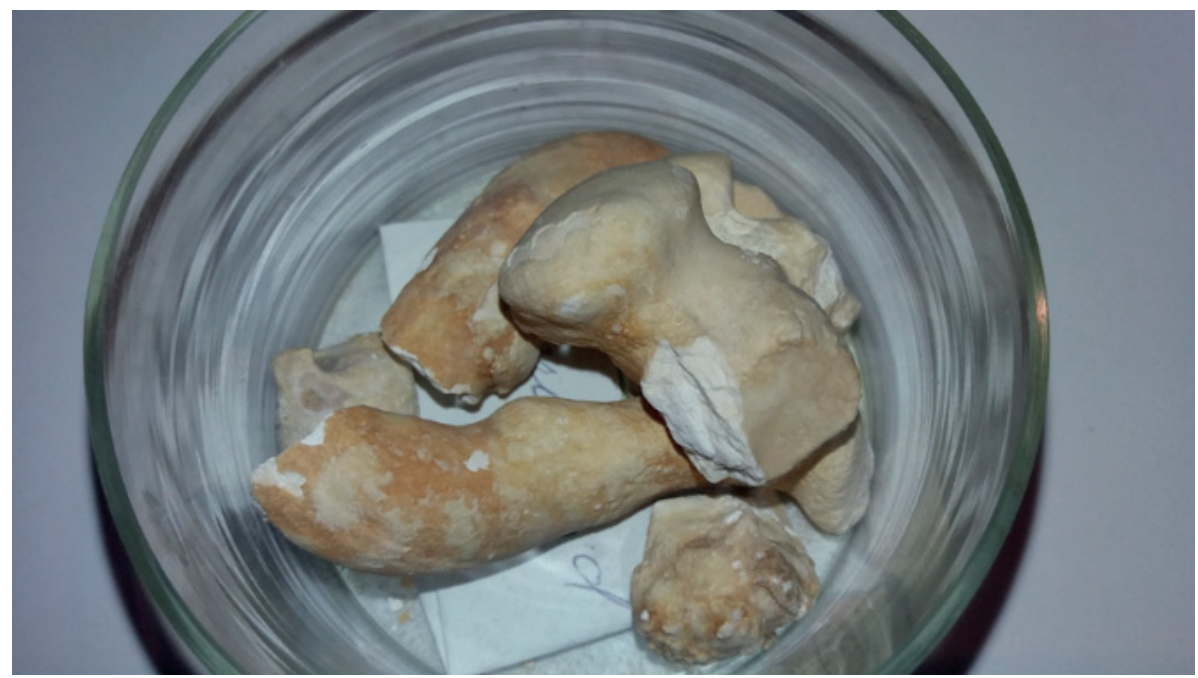

Human kidney stones 
The Science Centre AHHAA has provided facilities for showing thematic films and technical equipment for demonstrating the functioning of the human organism to visitors.
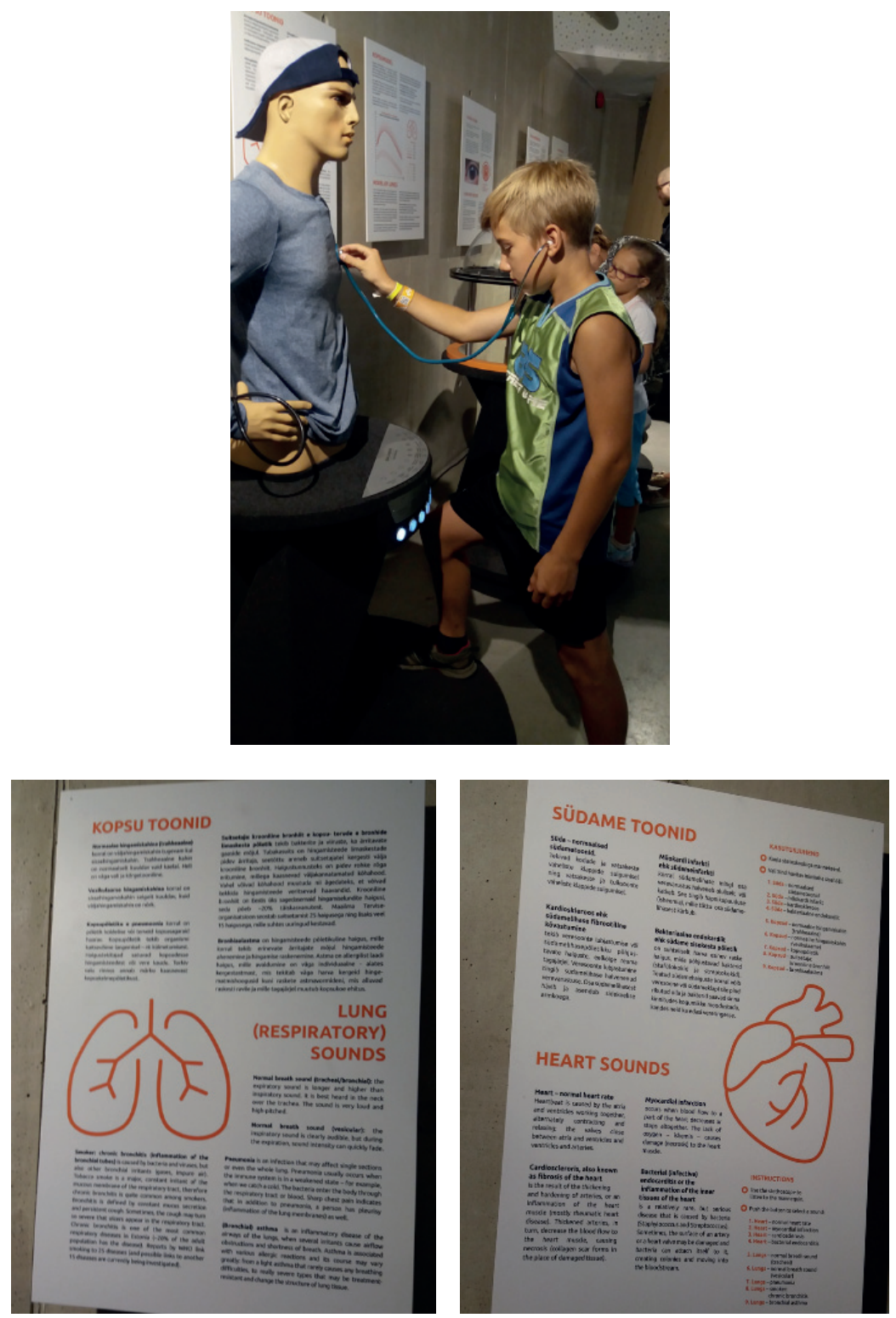

Model for auscultation of lung and heart sounds. Visitors can also auscultate the lungs of a bronchitis patient and a smoker. 


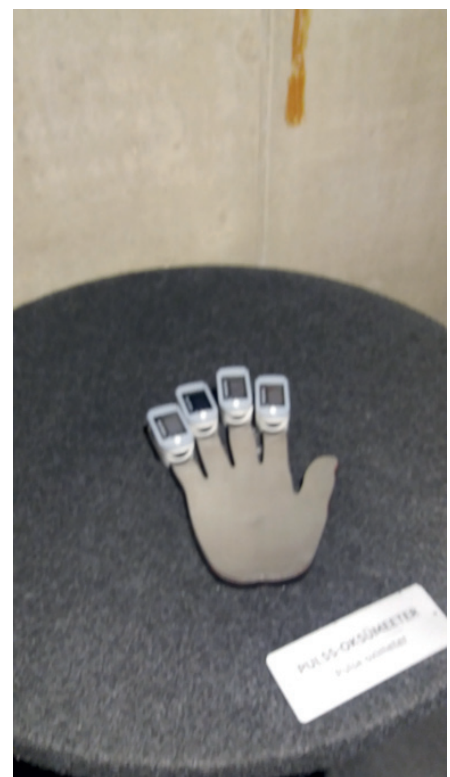

Pulse oximeter
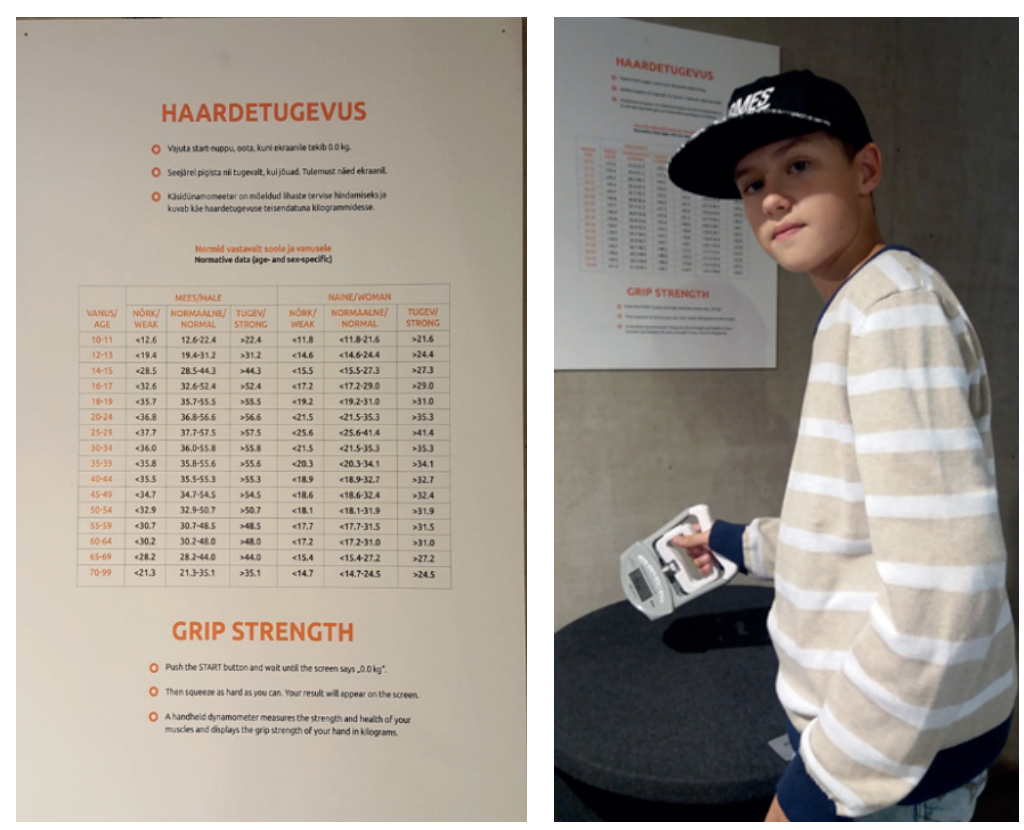

Measuring of grip strength

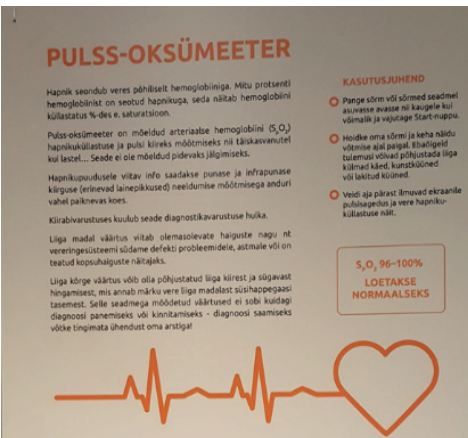

PULSE OXIMETER

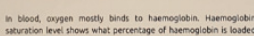

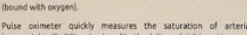

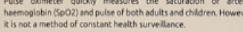

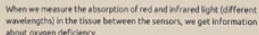
equentex

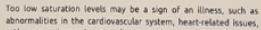

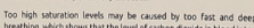

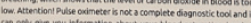

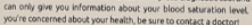
insthuctions

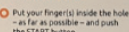

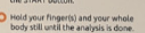

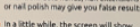

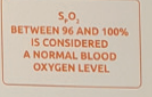



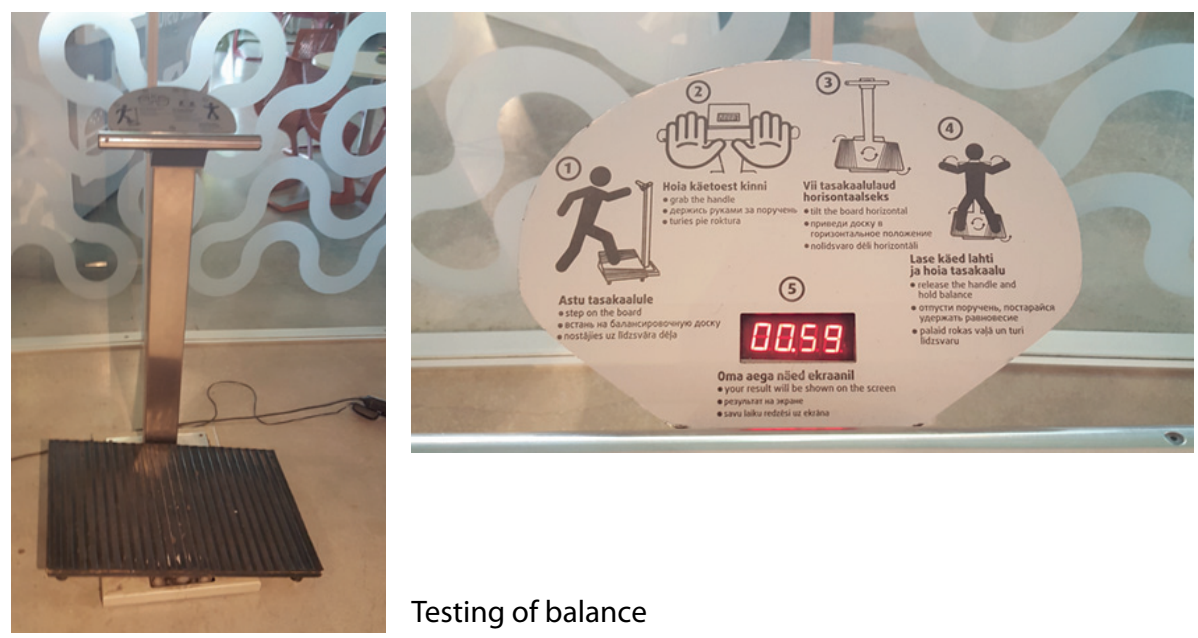

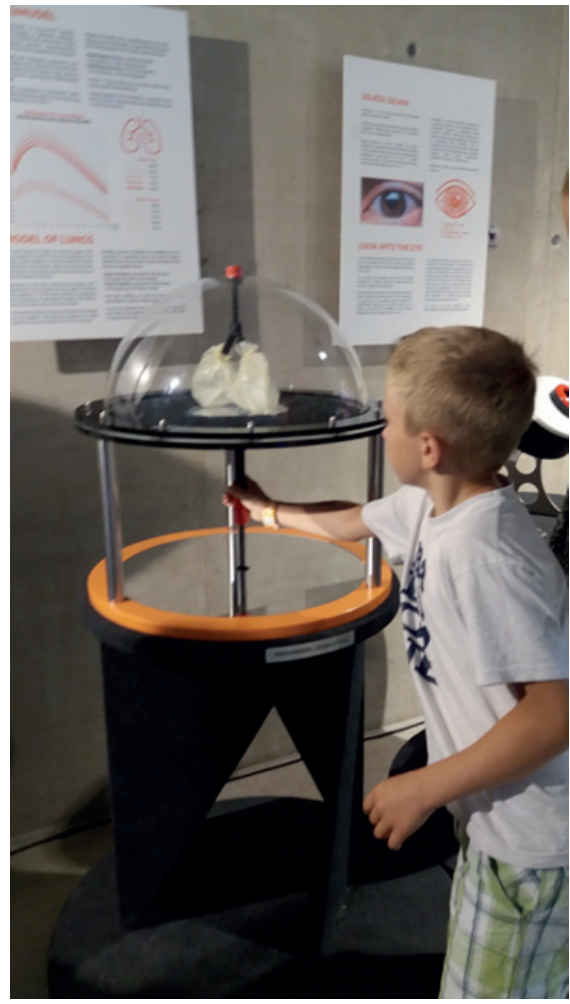

Explanation of the functioning of the lung

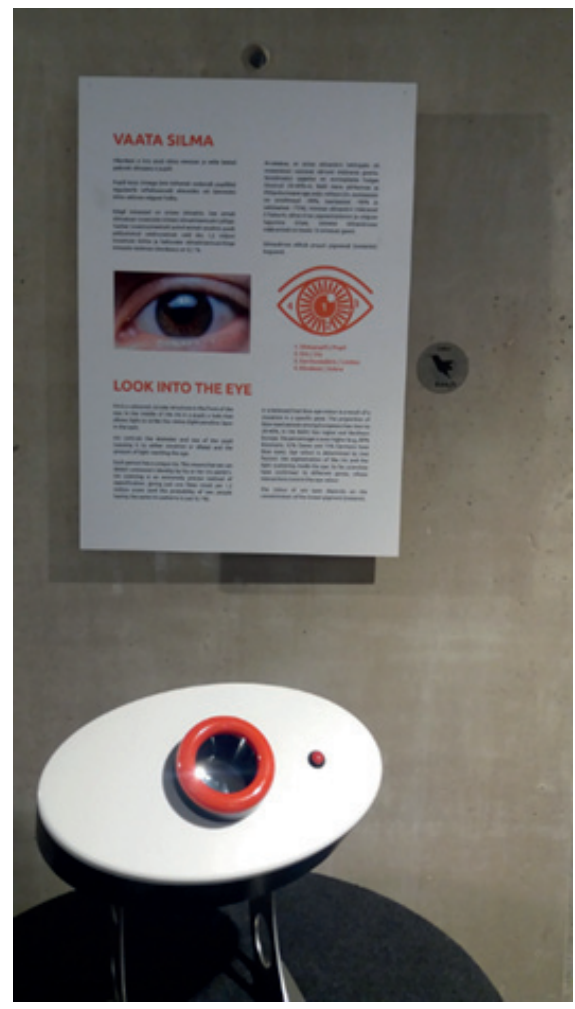

Explanation of the functioning of the eye 

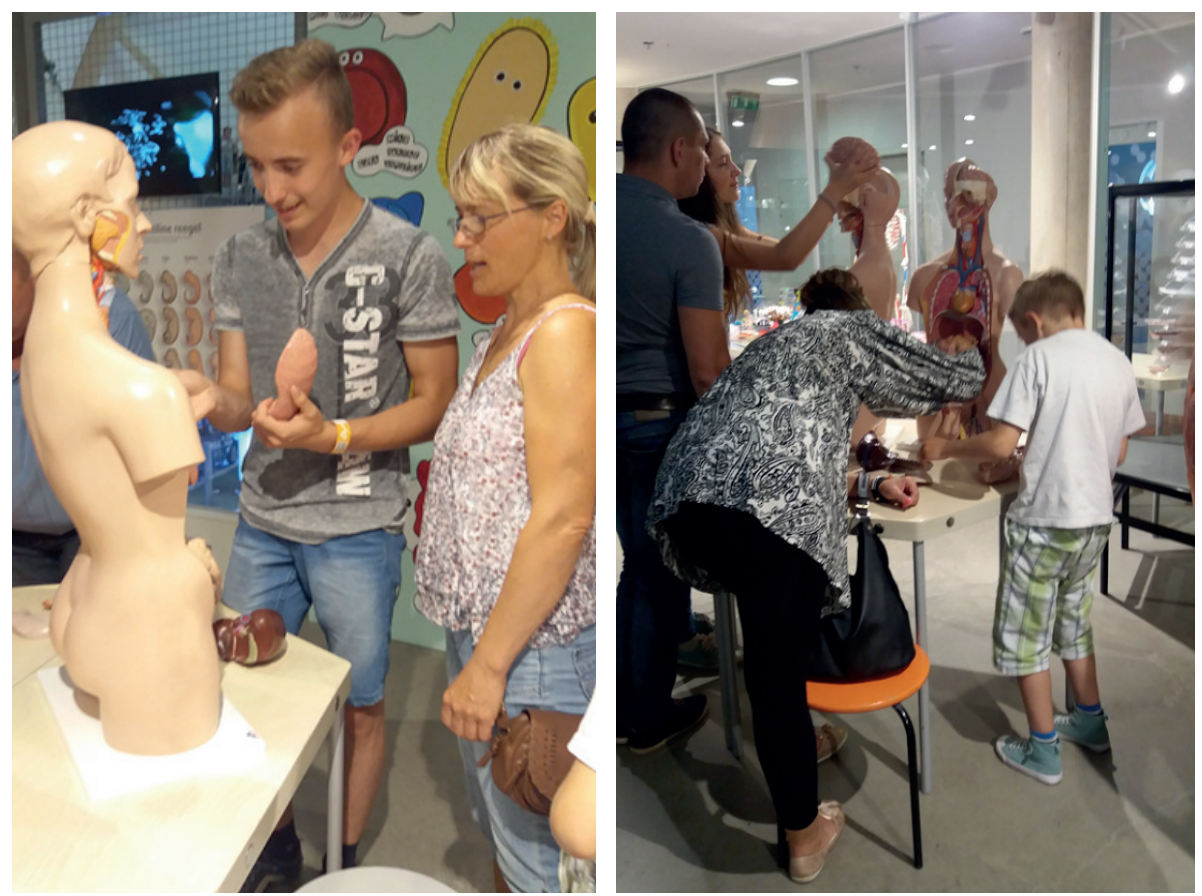

Human models are highly popular. They are assembled individually or by families. At weekends queues gather to assemble models under the guidance of the staff.

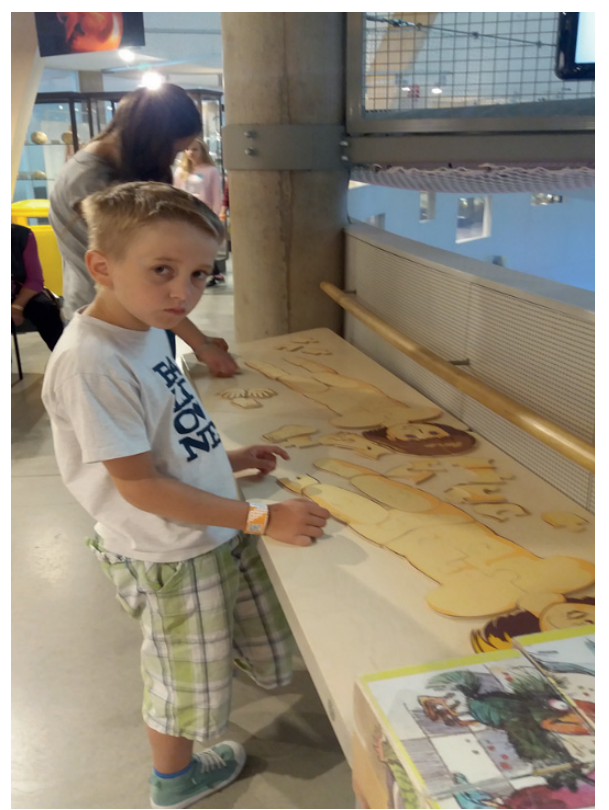

Human puzzle for children

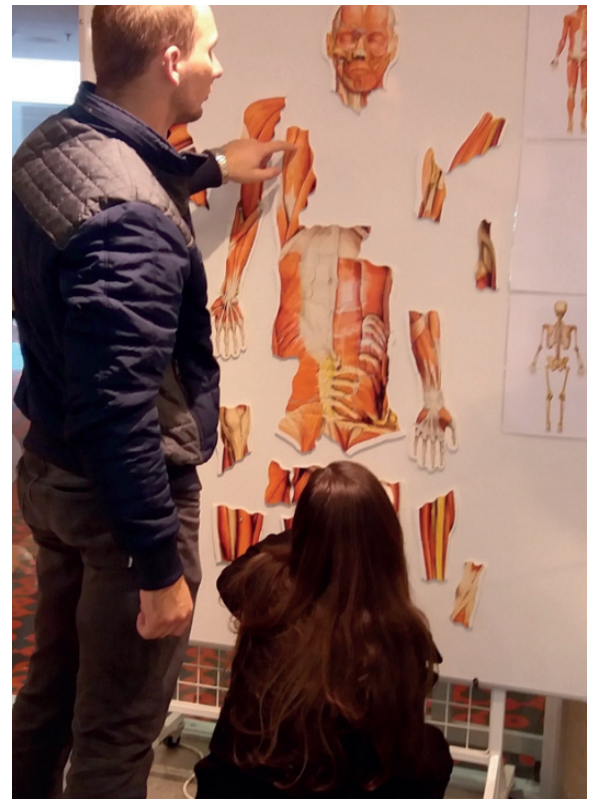

Muscle puzzle and skeleton puzzle 
Human puzzles are assembled attentively. There are simpler and more sophisticated variants of them.

An interesting addition to the exhibition is the AHHAA skeleton camera.

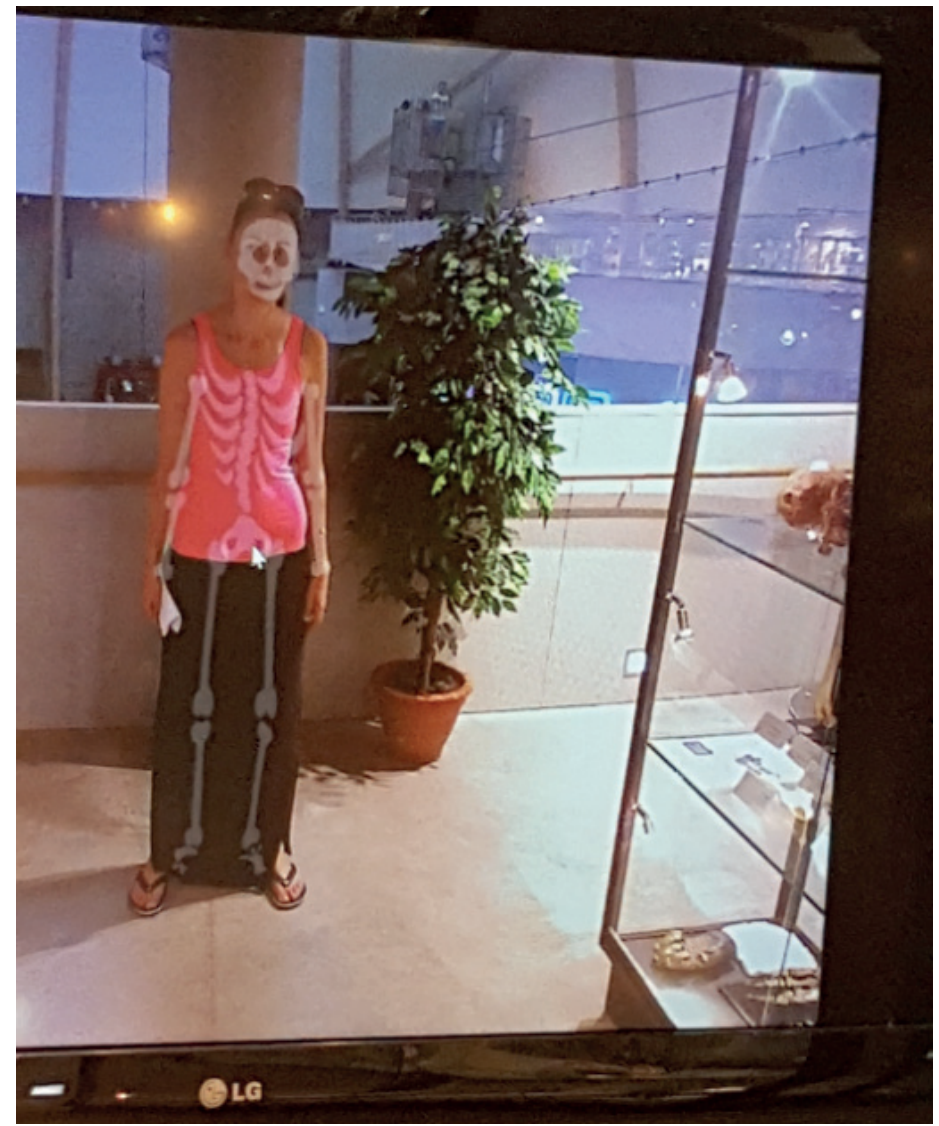

School students can participate in the educational programme "The Human". 
The educational programmes for schoolchildren are directed by Pille Randjärv. After the tour of medical collections, students can solve tasks.
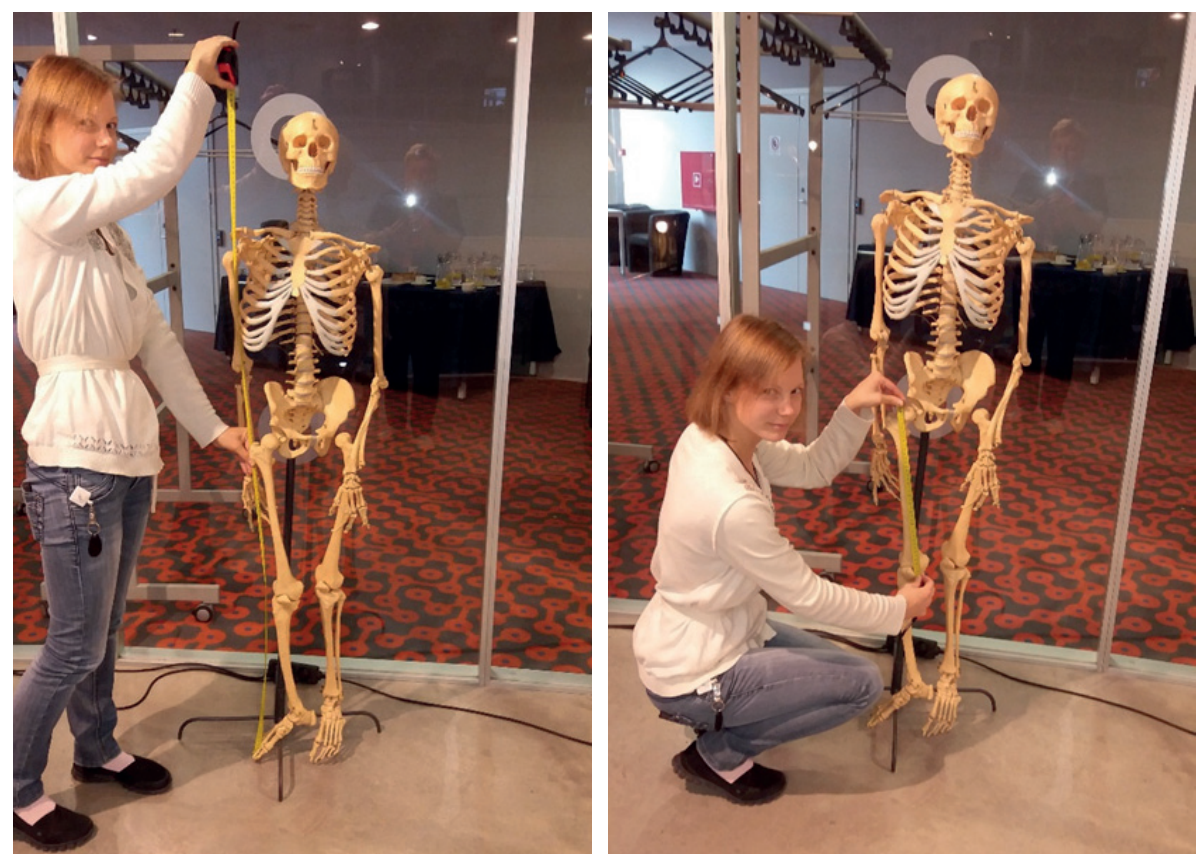

Tasks for investigation of oneself.

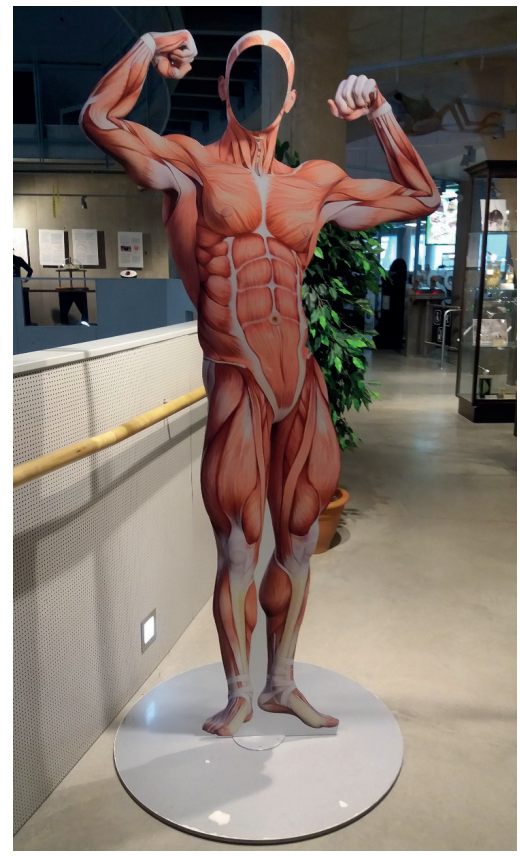

Muscleman anatomical model 

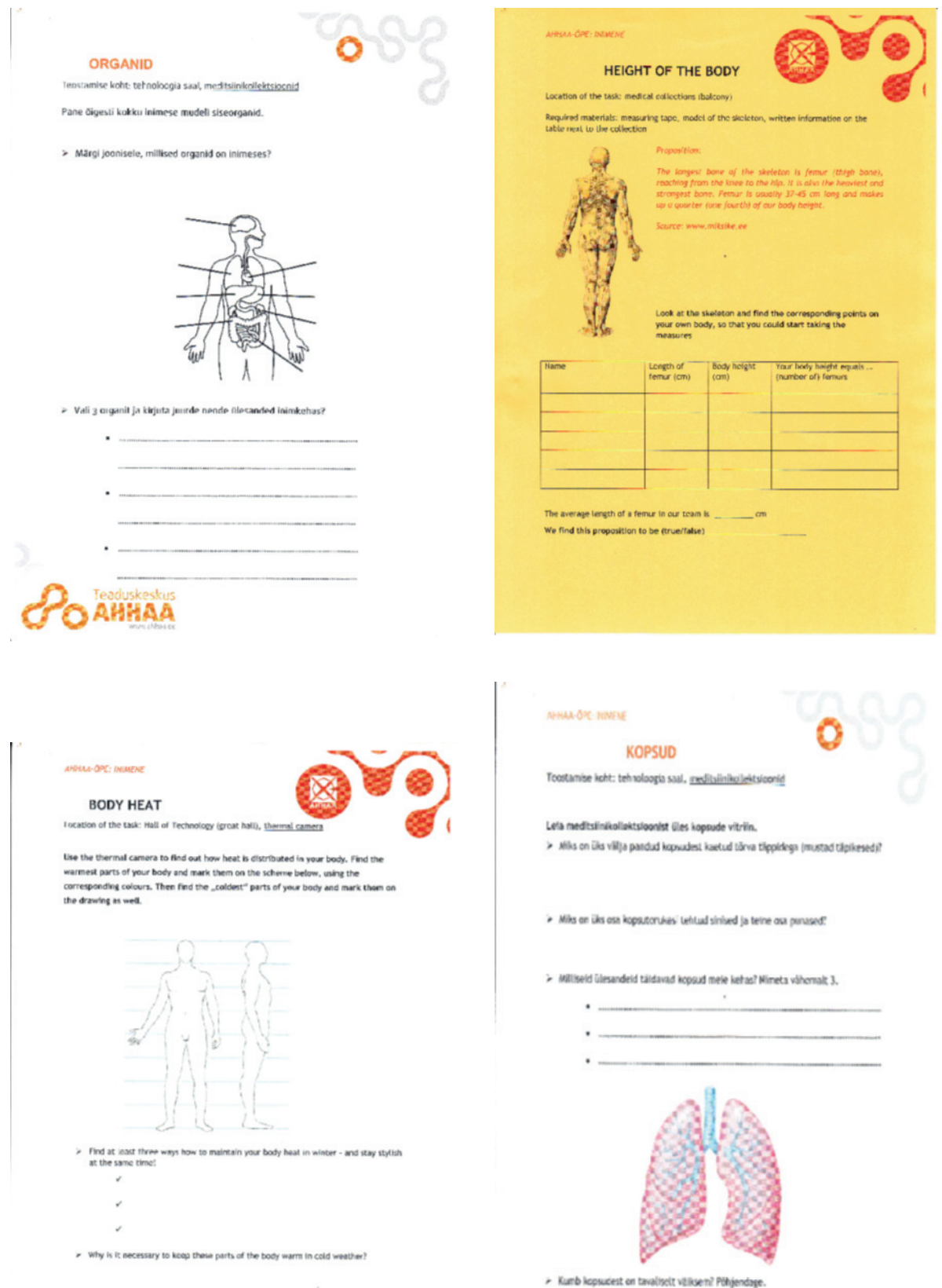

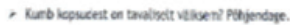


This is followed by a practical workshop in the laboratory where a pig's lung or a pig's heart is dissected. The teacher explains in detail the structure and functioning principles of the selected organ. All children are provided with protective clothing and rubber gloves.
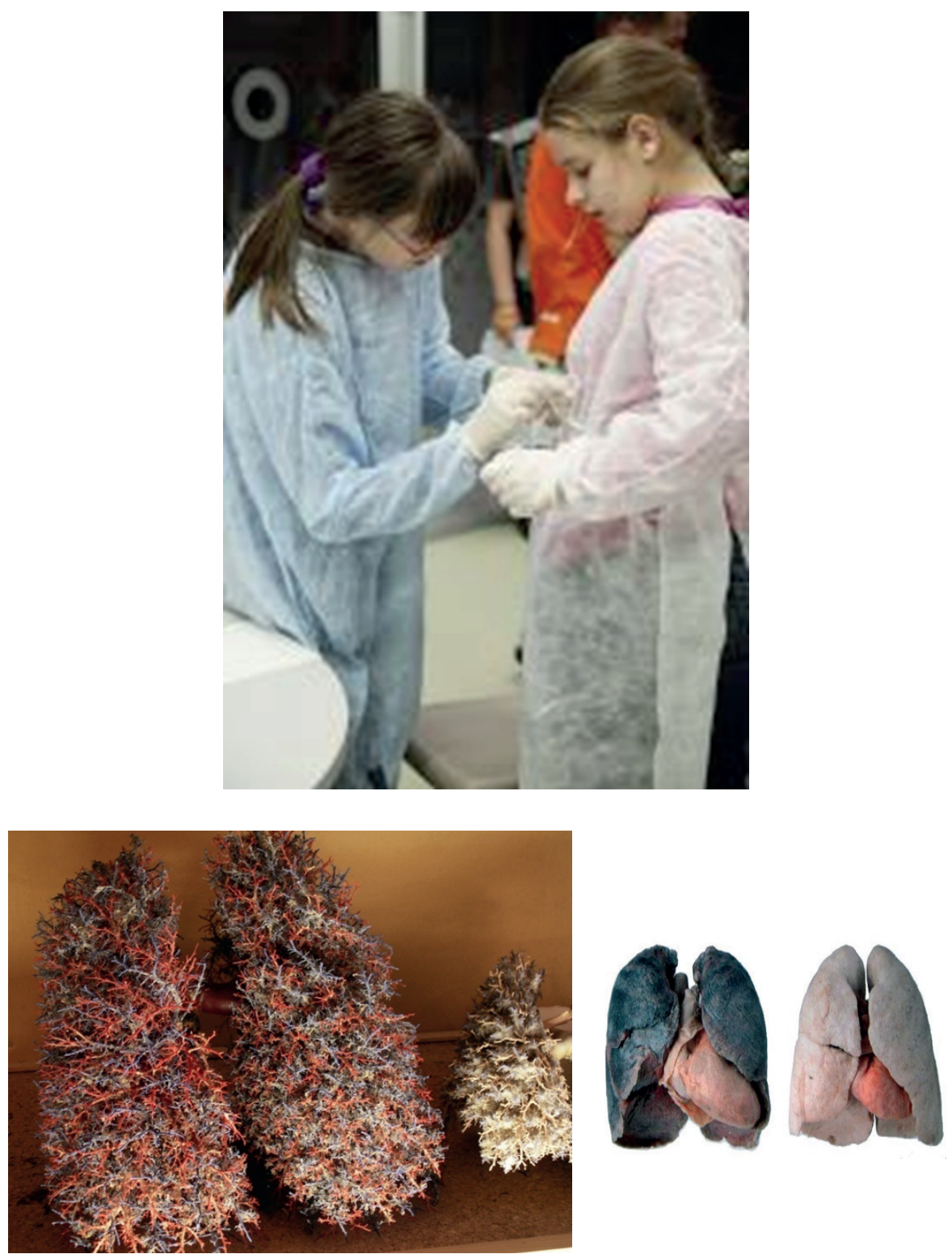

The structure of the lung is explained. 

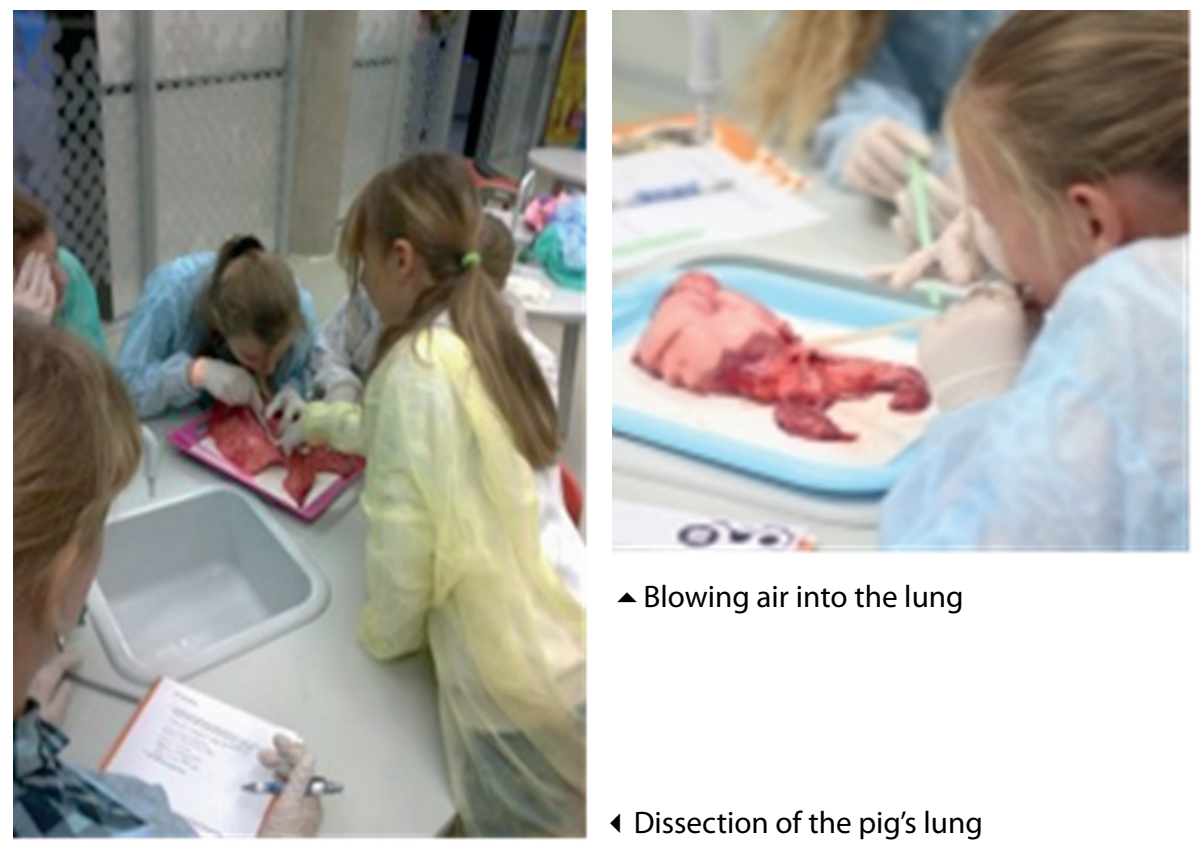

- Blowing air into the lung

Dissection of the pig's lung

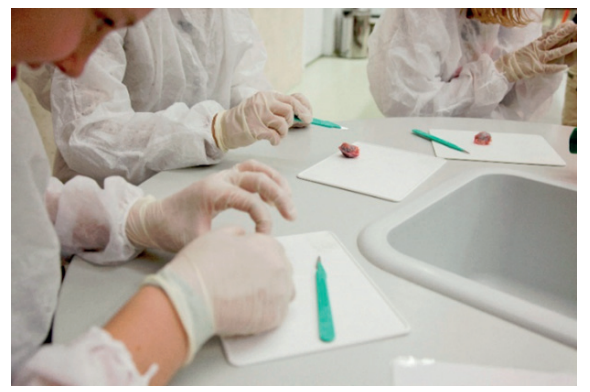

Dissection of the pig's eye

The AHHAA effect - a moment of discovery and surprise - is always present. ।

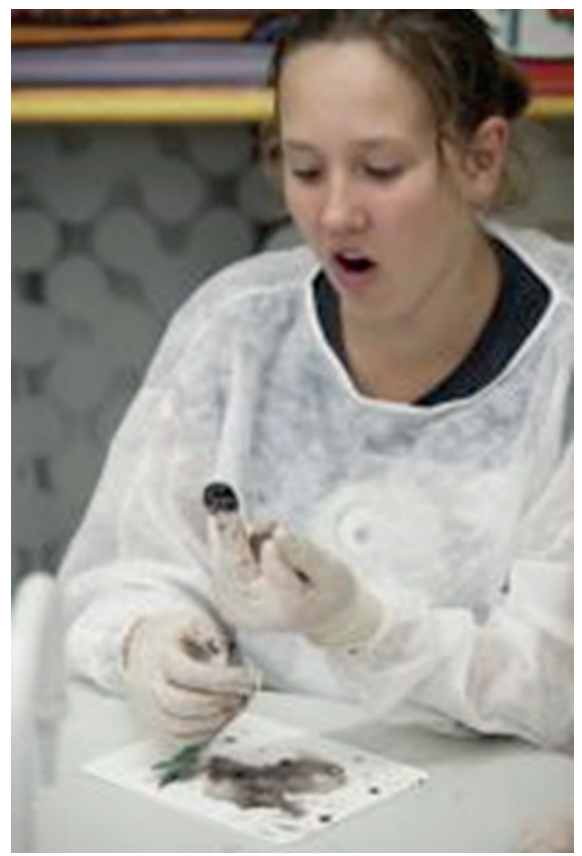


The day also includes AHHAA science theatre. Depending on the age of students, science theatre programmes are performed: "From Cake to Poop". In the science theatre, one can learn about the human being's digestion.

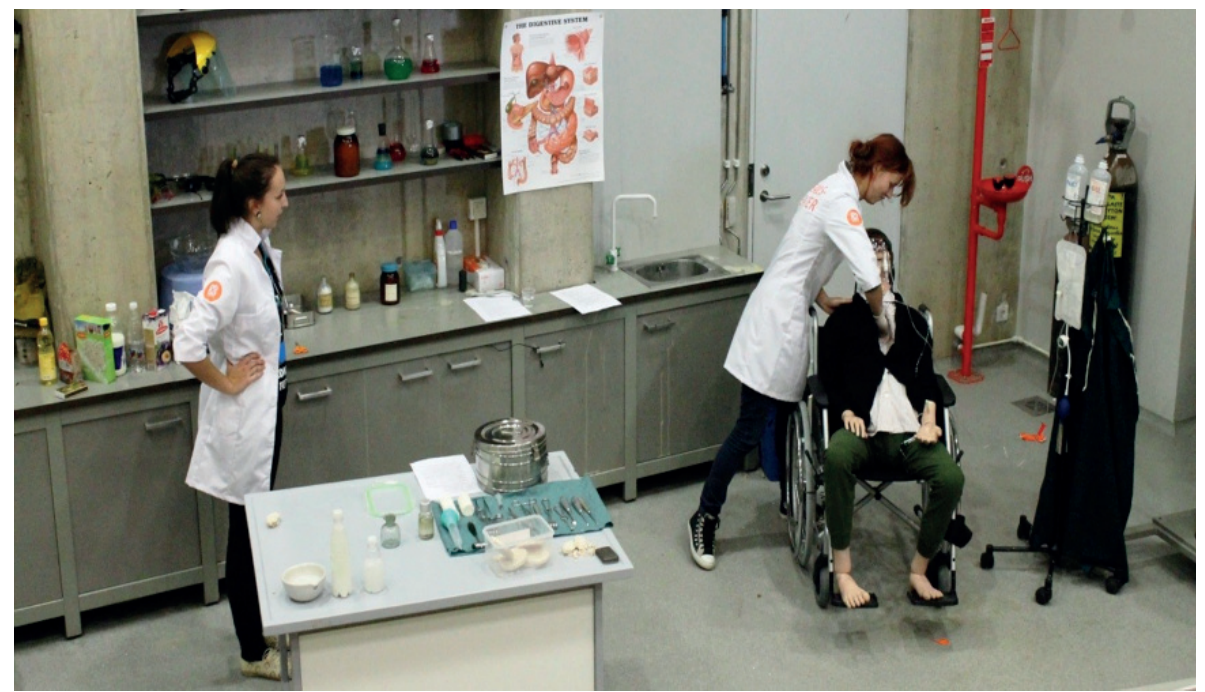

Science theatre performance "From Cake to Poop"

The study day ends with a summing-up where participants can point out what they personally learned on that day or what was new for them.
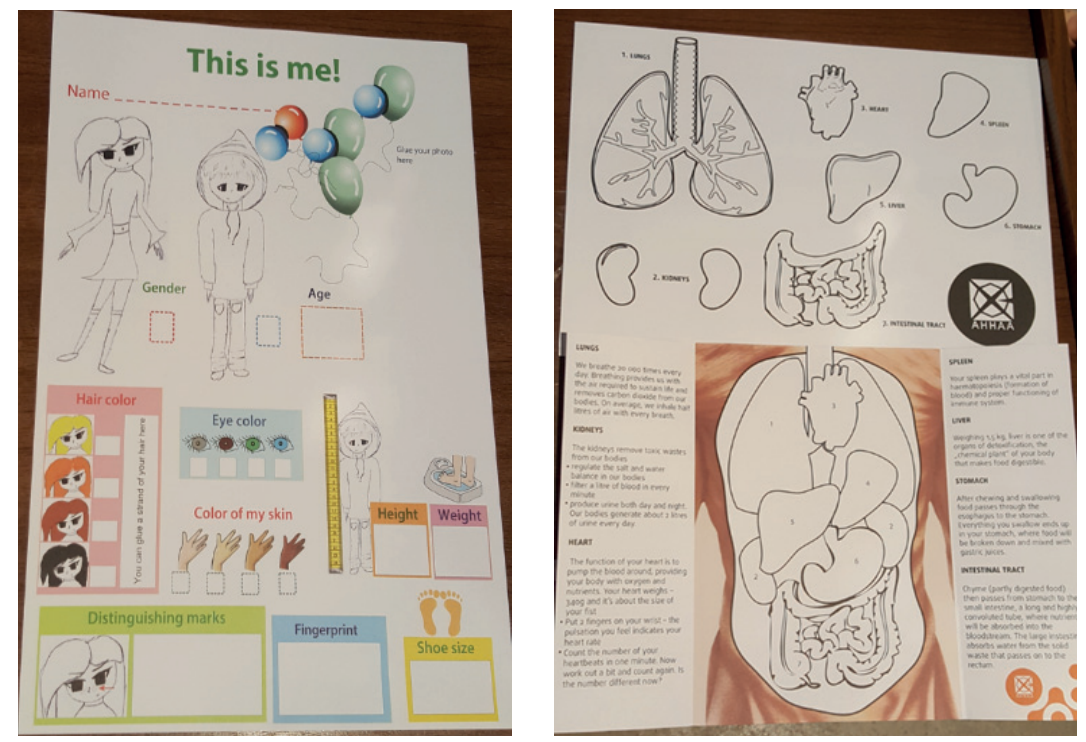
Young children have also been taught with worksheets (see below) and human models only. Worksheets are popular with adult visitors as well. They have been compiled in the languages of the main visitor groups: Estonian, Russian, English, Latvian and Lithuanian. Worksheets in Finnish are in preparation.

The medical collections are always busy, as the AHHAA Science Centre is a popular place. Last year, the Centre had 226,000 visitors from the whole world. We have fans from several countries who visit us recurrently and bring along new friends. It is sheer joy for the staff of the collections if visitors come to the medical collections repeatedly during the day and always ask new questions, as this shows that people are interested. If the advice has been helpful, they come and express their thanks.
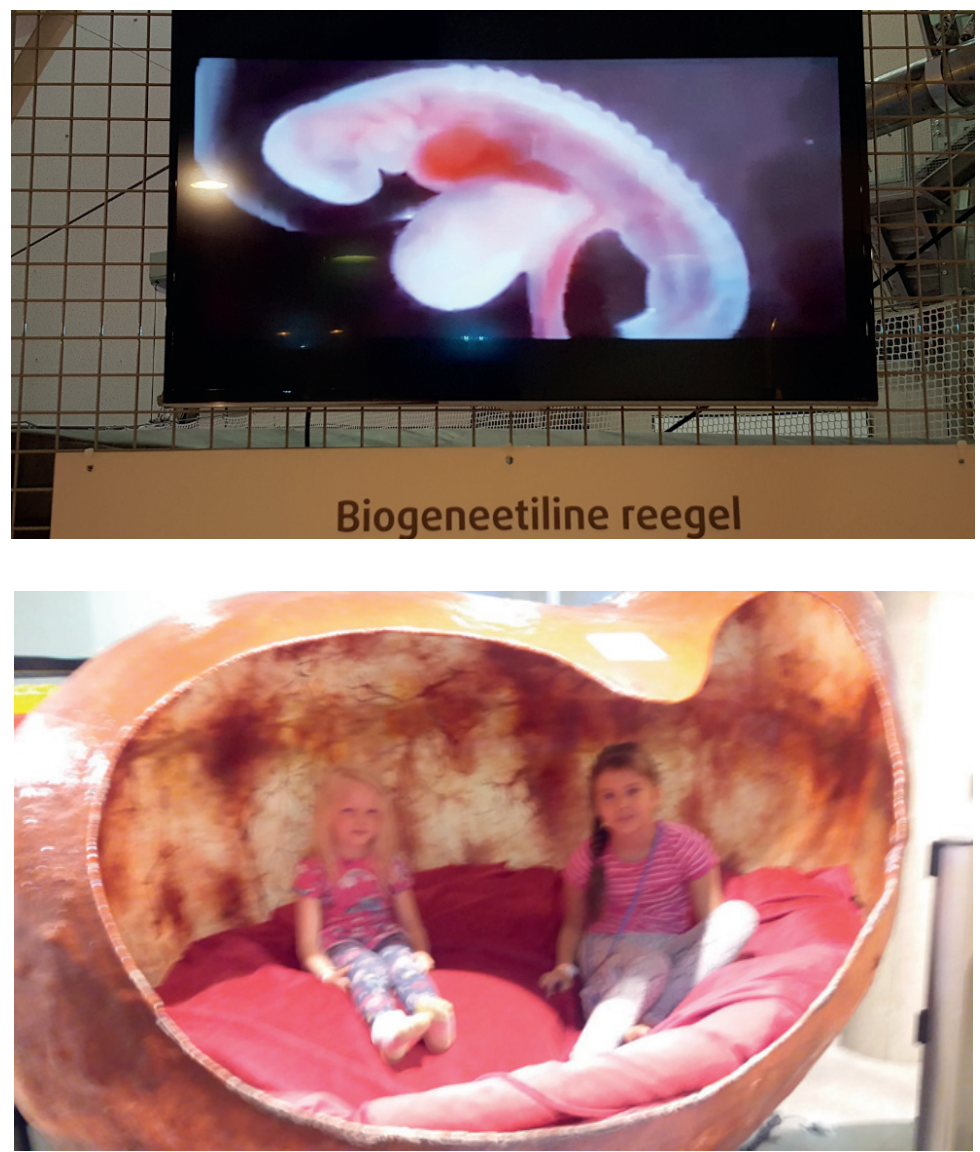

When the wonder how children come to this world has been understood, one can take a peaceful rest in the mother's womb created by the artist Kristiina Viin. 
As the medical collections lack base funding, thematic souvenirs are sold to purchase materials necessary for taking care of the collections.

In conclusion, it can be said that in the 21 st century the study hall that initially was meant to illustrate lectures has become a multifunctional place of edutainment. It has become a place where families and children spend their free time, school and university students study; doctors recall the time of their studies and revise what they have learned. The exhibition has become a place where the exhibits influence people's emotions, giving them confidence or inspiring them to make changes in their lives. The medical exhibition has also become a place for self-reflection. Attempts are made to get schoolchildren interested in biology and medicine, which has caused great competition among those who would like to take up studies of medicine at the university.

Professor of Anatomy August Antonius Rauber would definitely be most satisfied seeing that his ideas are alive.

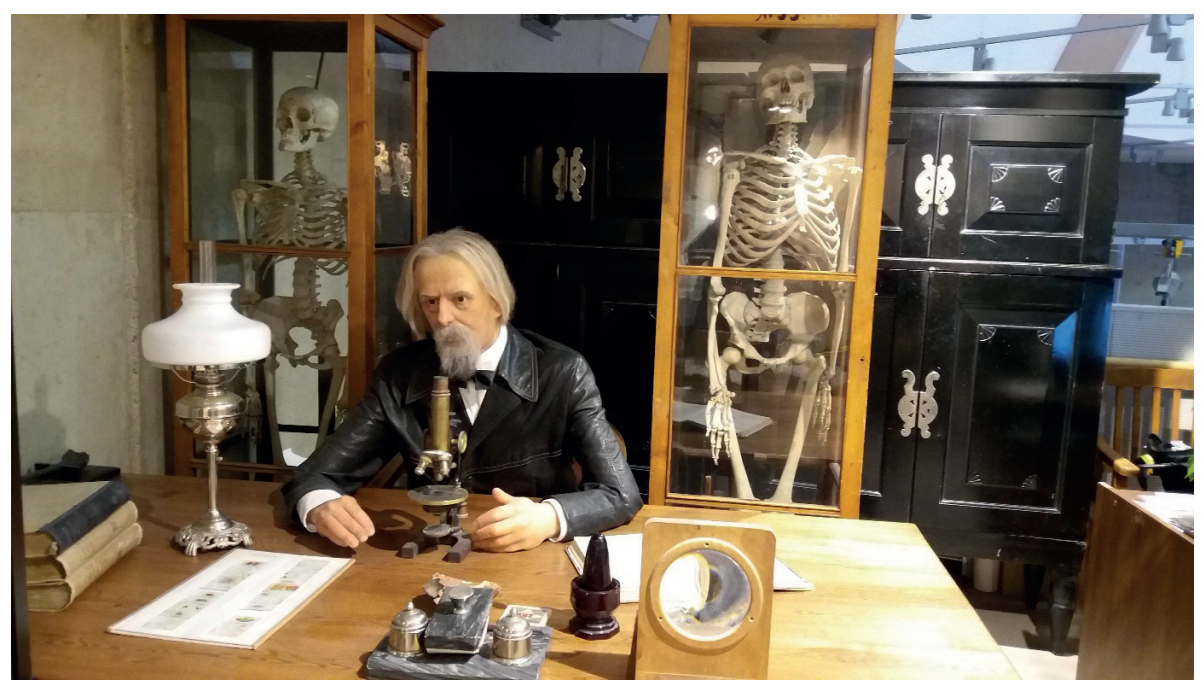

August Antonius Rauber at the exhibition 


\section{REFERENCES}

1. Rauber A.A. (1895). Ueber die Einrichtung von Studiensälen in anatomischen Instituten. Mit einer photographischen Tafel. Leipzig: Besolds Verlag.

\section{Address for correspondence:}

Maie Toomsalu

Department of Anatomy

Institute of Biomedicine and Translational Medicine

Ravila Street 19, 51014 Tartu, Estonia

maie.toomsalu@ut.ee 